\title{
2009 Continued Testing of the Orion Atmosphere Revitalization Technology
}

\author{
Amy B. Button ${ }^{1}$ \\ Engineering and Science Contract Group/Jacobs Technology, Houston, Texas, 77058 \\ and \\ Jeffrey J. Sweterlitsch ${ }^{2}$ \\ NASA Johnson Space Center, Houston, Texas, 77058
}

\begin{abstract}
An amine-based carbon dioxide $\left(\mathrm{CO}_{2}\right)$ and water vapor sorbent in pressure-swing regenerable beds has been developed by Hamilton Sundstrand and baselined for the Orion Atmosphere Revitalization System (ARS). In three previous years at this conference, reports were presented on extensive Johnson Space Center (JSC) testing of this technology in a sea-level pressure environment, with simulated and real human metabolic loads, in both open and closed-loop configurations. The test article design was iterated a third time before the latest series of such tests, which was performed in the first half of 2009. The new design incorporates a canister configuration modification for overall unit compactness and reduced pressure drop, as well as a new process flow control valve that incorporates both compressed gas purge and dual-end vacuum desorption capabilities. This newest test article is very similar to the flight article designs. Baseline tests of the new unit were performed to compare its performance to that of the previous test articles. Testing of compressed gas purge operations helped refine launchpad operating condition recommendations developed in earlier testing. Operating conditions used in flight program computer models were tested to validate the model projections. Specific operating conditions that were recommended by the JSC test team based on past test results were also tested for validation. The effects of vacuum regeneration line pressure on resulting cabin conditions was studied for high metabolic load periods, and a maximum pressure is recommended.
\end{abstract}

\section{Nomenclature}

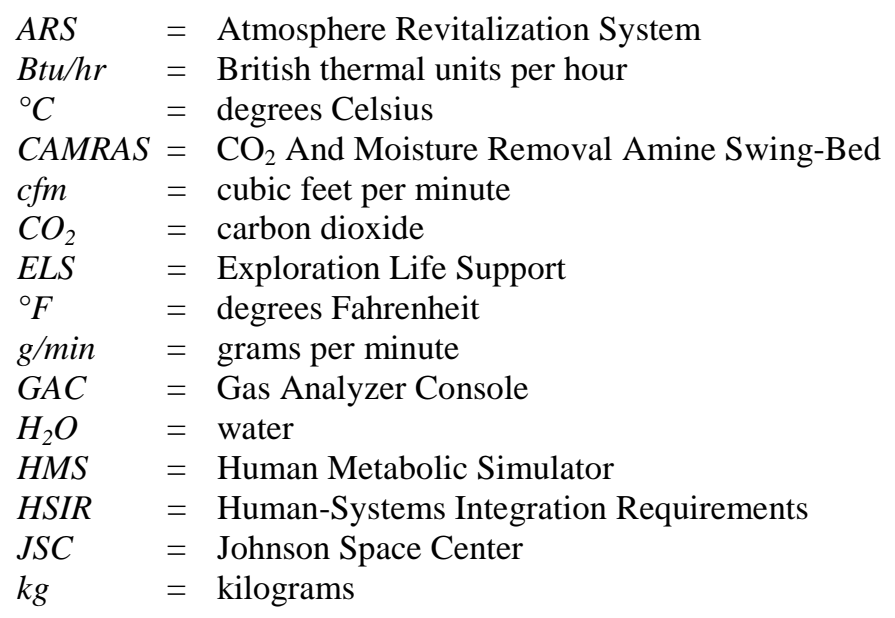

${ }^{1}$ Project Engineer, Exploration Life Support Atmosphere Revitalization Systems, 2224 Bay Area Boulevard, Mail Code JE77, AIAA Lifetime Member.

${ }^{2}$ Project Engineer, Exploration Life Support Atmosphere Revitalization Systems, 2101 Nasa Parkway, Mail Code EC3, not an AIAA Member. 


$\begin{array}{ll}\mathrm{kPa} & =\text { kilopascals } \\ \mathrm{lpm} & =\text { liters per minute } \\ \mathrm{min} & =\text { minutes } \\ \mathrm{mmHg} & =\text { millimeters of mercury } \\ \mathrm{Pa} & =\text { Pascals } \\ \text { ppCO } & =\text { partial pressure of carbon dioxide } \\ \text { psia } & =\text { pounds per square inch, absolute } \\ \text { psid } & =\text { pounds per square inch, differential }\end{array}$

\section{Introduction}

Human beings produce carbon dioxide $\left(\mathrm{CO}_{2}\right)$ when they breathe, but too high a concentration in the atmosphere around them can quickly become toxic. For this reason, $\mathrm{CO}_{2}$ control is critical in the closed environment of a spacecraft. Humans also exhale water vapor and exchange water vapor with the atmosphere through their skin. Although excessive water $\left(\mathrm{H}_{2} \mathrm{O}\right)$ vapor is not dangerous to humans, it can be uncomfortable, and it can be hazardous to the electronic equipment in a spacecraft cabin, particularly if it condenses in undesired locations.

In the past, spacecraft have typically used separate systems to control $\mathrm{CO}_{2}$ and humidity. $\mathrm{CO}_{2}$ control methods have included sorption by lithium hydroxide or zeolite compounds, and water has typically been collected by condensing heat exchangers. However, those $\mathrm{CO}_{2}$ sorption systems have tended to be large and heavy, whether regenerable or not, and condensate water collection systems require a lower temperature thermal control system with a large heat capacity.

As an alternative to traditional $\mathrm{CO}_{2}$ sorption systems, Hamilton Sundstrand has spent many years developing amine-based vacuum-regenerated adsorption systems. The first major implementation of this type of system, known as the Regenerative $\mathrm{CO}_{2}$ Removal System, was tested on the Space Shuttle in the early 1990s. This design and the associated sorbent amine have since gone through a number of improvement cycles. The current iteration of the system uses a pair of interleaved-layer beds filled with SA9T, which is a sorbent system comprised of plastic beads coated with an amine.

SA9T, in addition to being a good $\mathrm{CO}_{2}$ sorbent, also has a great affinity for water vapor. When water vapor is removed from the cabin atmosphere with a regenerable sorbent instead of a traditional condensing heat exchanger, the spacecraft cooling system can be greatly simplified by eliminating a fairly significant heat load as well as the need for a low-temperature cooling loop. The interleaved bed system also minimizes total cabin heat loads due to the adsorption and desorption processes. Hamilton Sundstrand studies have shown SA9T to be very stable over long periods. For these and other reasons, this technology has been baselined as the primary $\mathrm{CO}_{2}$ and water vapor removal device for the new Orion spacecraft.

While Hamilton Sundstrand's technology was already relatively well developed and had undergone subscale and open-loop testing, NASA's Exploration Life Support (ELS) and Orion Environmental Control and Life Support System development groups wanted more details on the performance of a full-scale device in a realistic spacecraft environment. The ELS Air Revitalization Systems team at Johnson Space Center (JSC) refitted an existing test chamber to test Hamilton Sundstrand's technology, which the Air Revitalization team calls the $\mathrm{CO}_{2}$ And Moisture Removal Amine Swing-bed, or CAMRAS.

The JSC team tested a single CAMRAS unit in two test phases in late 2006. The preliminary results of those tests were presented at this conference in 2007. A second CAMRAS unit of slightly-modified design was added to the system for the third phase of testing in mid-2007, and those results were presented at this conference in 2008. A third, significantly redesigned, CAMRAS unit with a new, more flight-like, valve style was tested in the ambientpressure portion of a fourth phase of tests during the spring of 2009, and those results are presented in this paper. A second portion of the fourth phase, reduced-pressure testing of many of the same cases, is planned for mid- 2010 .

\section{Test Rig Description}

To evaluate the CAMRAS for Orion use, it was placed in a controllable, well-mixed atmosphere of the appropriate volume. A motive force for airflow through the amine beds and a vacuum source to simulate a link to space vacuum was provided, as was a supply of dry pressurized air representing a launchpad regeneration capability. The effects of humans on the cabin atmosphere were simulated with a Human Metabolic Simulator (HMS), and the whole test rig was outfitted with various sensors to monitor test conditions and experimental results. Figure 1 shows a simple diagram of the test rig described in this section. 
Air flowed from the process loop inlet past a filter, flow meter, and several sensors before passing into the CAMRAS air inlet port on the top of the unit. Air flowed out of the CAMRAS unit through another line, where several more sensors were located. The blower outlet air was passed over another thermocouple as it returned to the chamber atmosphere. External gas analyzer consoles (GACs) monitored sample gas streams from the chamber atmosphere and from the CAMRAS inlet and outlet lines, and all samples were returned to the chamber.

\section{A. Test Article}

In each CAMRAS unit, a valve directs airflow from the cabin through the adsorbing bed layers and back to the cabin, while isolating the desorbing bed layers to a direct line to space vacuum. The highly porous plastic beads in this next-generation device are coated with a liquid amine, which becomes immobilized in the bead pores. In this SA9T sorbent, both carbon dioxide and water are adsorbed simultaneously and somewhat independently. The $\mathrm{CO}_{2}$ adsorption reaction generates some heat, while the desorption reaction consumes heat;

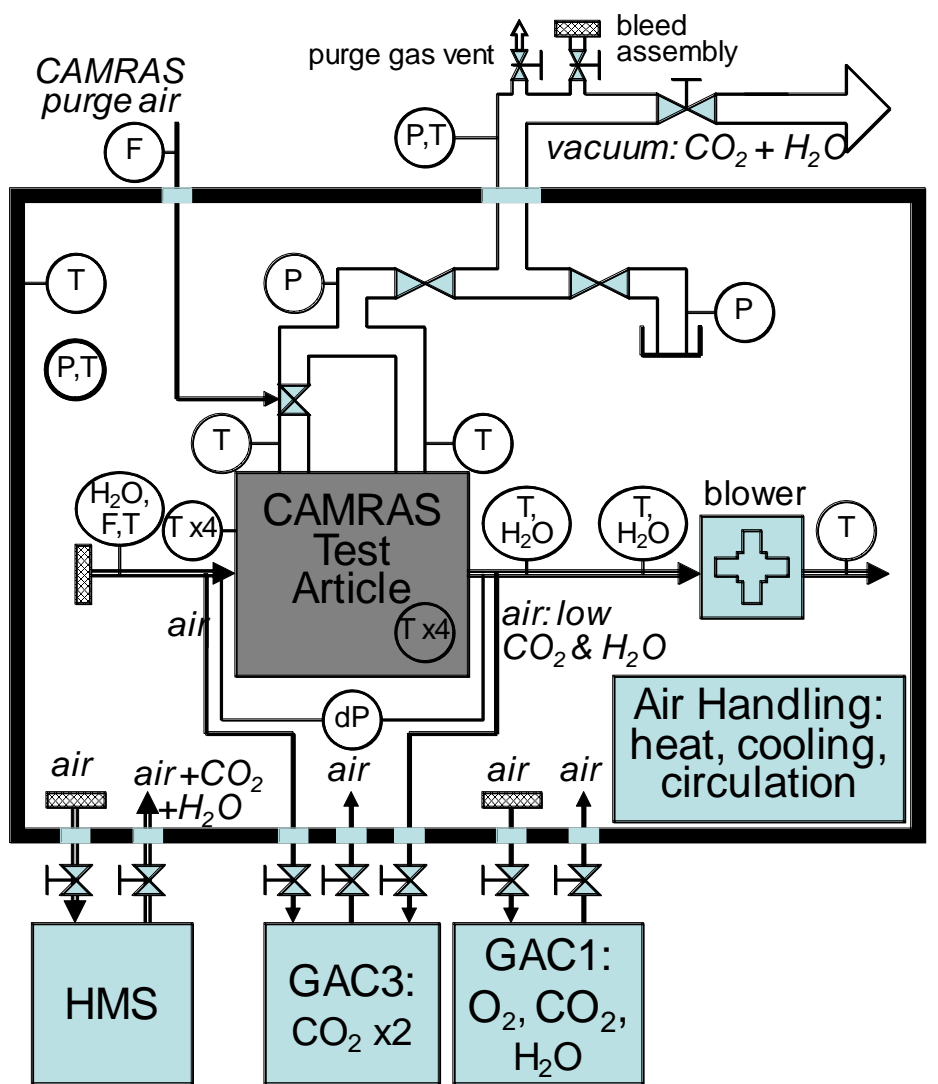

the interleaving of bed layers helps conserve the overall system thermal energy so that no active heating or cooling

Figure 1. CAMRAS Phase 4A simplified test rig schematic.

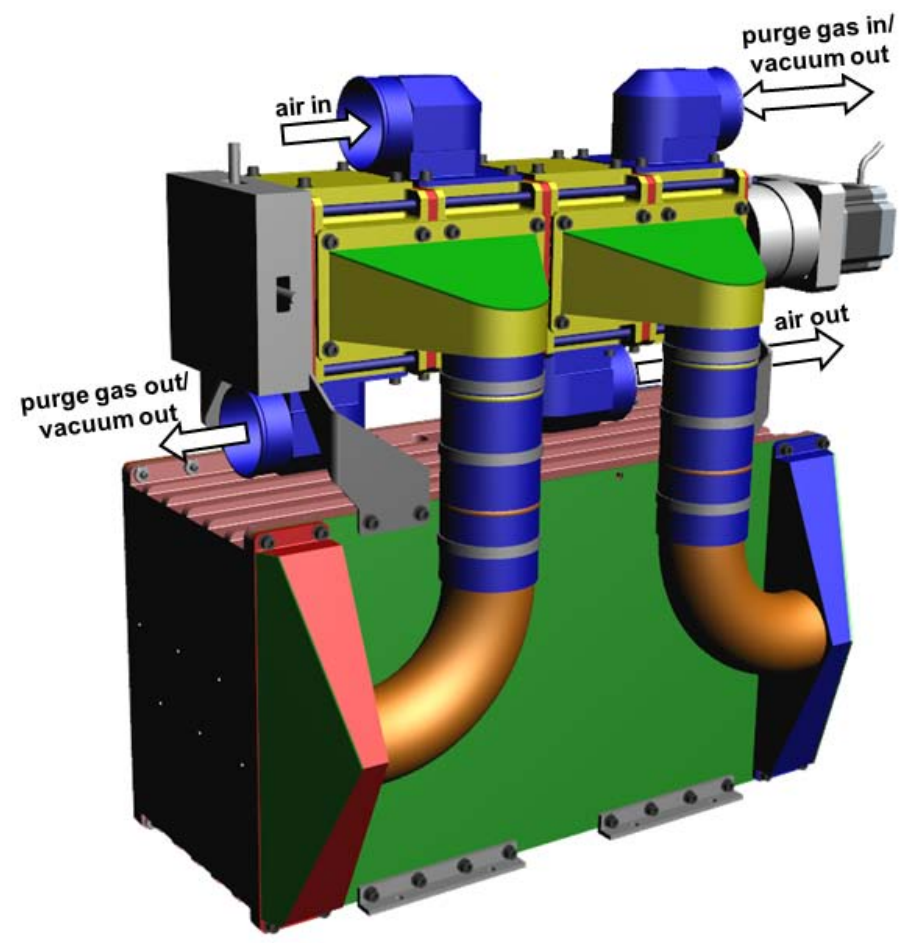
of the unit is required.

The previous CAMRAS design used a spool-type valve to direct gas through the adsorbing and desorbing beds, equalizing pressure between them as it transitioned from one end of its path to the other. A gas purge could drive desorption for launch pad operations at the cost of restricting the vacuum desorption to a single end of each bed. The new design tested in CAMRAS Phase 4A, CAMRAS unit 3 (Fig. 2), uses a linear multiball valve, in which four ball valves with alternating port orientations are linked together for actuation by a single motor. The chain of valves rotates $270^{\circ}$ between two positions, equalizing pressure between the adsorbing and desorbing beds as it turns. Figure 3 shows a simple schematic of these new rotary valve flow paths with vacuum desorption. This new valve also allows purge gas to be pushed into one of the vacuum ports and out the other for launch pad operations while maintaining the capability to vacuum desorb the beds from both ends when the vehicle is on orbit.

Figure 2. CAMRAS unit 3.

American Institute of Aeronautics and Astronautics 


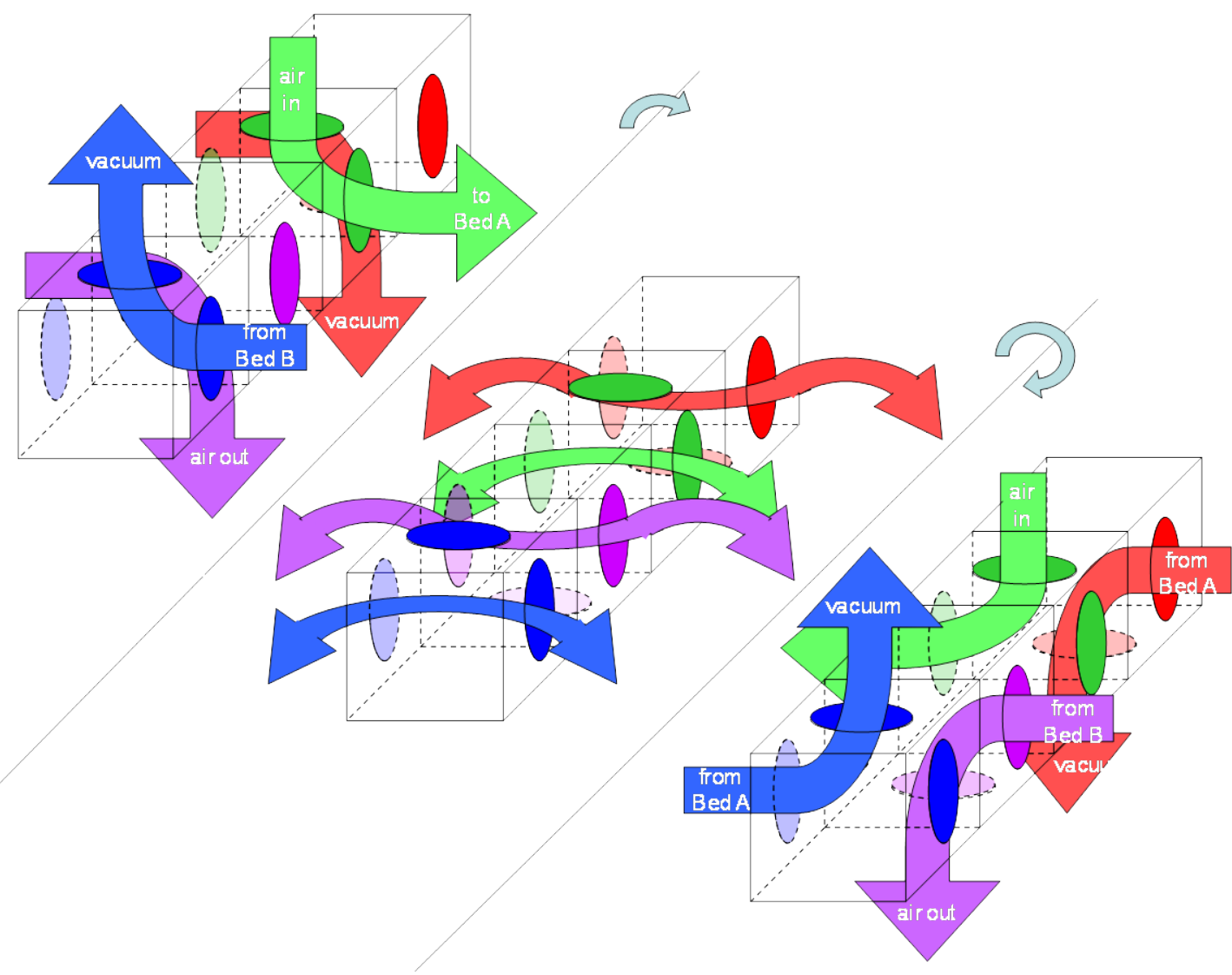

Figure 3. CAMRAS rotary linear multiball valve flow paths.

\section{B. Test Chamber}

The test chamber was a closed and sealed environment directly monitored for temperature and pressure. Air conditions in the chamber were also analyzed by an external sampling rack (Gas Analyzer Console 1, or GAC1) for dew point and for $\mathrm{CO}_{2}$ and $\mathrm{O}_{2}$ concentrations. Inside the chamber, a condensing heat exchanger with blower was operated with the coolant loop above condensing temperatures to both control temperature and provide ambient circulation. The total free volume of the chamber test volume was approximately $16.14 \mathrm{~m}^{3}$. The nominal Orion configuration calls for operation of two CAMRAS units, so for most CAMRAS Phase 4A test cases, which only used one unit, the chamber free volume was further reduced with airtight space-filling boxes to about $8.05 \mathrm{~m}^{3}$, or half the projected vehicle free volume. The chamber leak rate at the beginning of the Phase 4A testing was measured at an average $8.9 \%$ per day by a $\mathrm{CO}_{2}$ decay test with all external air loop systems (analyzers, metabolic simulator) circulating air out from and back into the chamber and the volume fillers installed.

\section{Metabolic Simulation}

A Human Metabolic Simulator (HMS) was used with the chamber for this testing. It was designed to simulate human production of $\mathrm{CO}_{2}$ and exhaled $\mathrm{H}_{2} \mathrm{O}$ vapor. Liquid water was pumped into a hot oil/water heat exchanger at a metered rate, the resulting steam was controlled to achieve slight pressurization (up to about $69 \mathrm{kPa}$ gauge), and the steam was then injected directly into a chamber air circulation loop. $\mathrm{CO}_{2}$ was separately injected into the air loop from a pressurized and flow-controlled gas source.

The CAMRAS tests were typically run with simulated loads representing four or six people. ${ }^{*}$ Table 1 lists the metabolic constituent generation rates used in CAMRAS Phase 4A testing. These rates were usually halved for metabolic loads of two or three people with a single test article. The rates are based on the early 2007 version of NASA’s Human-Systems Integration Requirements² (HSIR) and represent 82-kg males.

\footnotetext{
${ }^{*}$ A six-person crew was eliminated from standard Orion operations plans, but this test series was already in progress when that change was implemented.
} 
Exercise scenarios were run with only four simulated people, as a crew of six would not have enough space to exercise in the Orion capsule. The metabolic loading provided by the HMS was increased from four at nominal level to three nominal plus one person exercising for the time period that it would take for the entire simulated crew to complete their exercises. Exercise for each crew member was simulated at $75 \%$ of maximum volumetric oxygen use rate and 5\% exercise efficiency for 30 minutes, with a 15-minute break between active exercise periods. Water generation rates for each simulated exerciser remained elevated for 60 minutes of cooldown time, where people would continue sweating after ceasing the actual exercise. To approximate real-life metabolic loading profiles, the HMS output rates were manually stepped up and down by prescribed amounts every 7.5 minutes for the nearly four hours required for all four exercise and cooldown periods.

\section{Test Article Air Flow}

Airflow through the CAMRAS could be controlled within a range of rates, depending on the experimental scenario, and it was designed to overcome the pressure drop caused by the plumbing fixtures and the amine beds themselves. Several sensors, including those measuring temperature, moisture, and airflow rate, were tapped into this plumbing stream. $\mathrm{CO}_{2}$ analysis was provided both upstream and downstream of the CAMRAS by external analyzers in closed sample loops. A cold trap upstream of each $\mathrm{CO}_{2}$ analyzer minimized the adverse effects of water vapor on the accuracy of the readings. The sample lines connected to both ends of the CAMRAS were crossconnected to enable cross-checks of the analyzer readings, and they were also fitted with connections to gas bottles that allowed the readings of the $\mathrm{CO}_{2}$ analyzers to be compared to a known standard on a daily basis. Both of these were intended to minimize unseen errors in the collected data.

\section{E. Test Article Regeneration}

In the flight environment of the Orion, the CAMRAS would be plumbed through a hole in the spacecraft shell, allowing it direct access to space vacuum for desorption of $\mathrm{CO}_{2}$ and $\mathrm{H}_{2} \mathrm{O}$ from the sorbent beds. Vacuum for the test was provided by a facility vacuum pump system. The vacuum flow path was fitted with pressure and temperature sensors to help characterize the CAMRAS performance. The vacuum line pressure near the CAMRAS unit could be varied within a small range to simulate the effects of long and small versus short and wide flow paths to space vacuum. This variability should help refine the Orion vacuum plumbing requirements and also allowed validation of performance models based on different vacuum pressures.

Phase 4A testing included testing of the gas purge option for desorption while the Orion vehicle would be sitting on the launch pad. A supply of dry compressed air was provided into the chamber, a flow controller allowed testing at different rates of gas flow, and the gas was vented to ambient pressure outside the building. A three-way valve on one of the CAMRAS unit's vacuum lines allowed purge gas to be pushed into that line or vacuum to be pulled on it, depending on the test case.

\section{Test Cases and Results}

Several different types of test cases were included in the Phase 4A series. At the beginning of every JSC CAMRAS test series, functional checkouts are run to ensure that the new test rig performs fundamentally the same as it did in prior test series and that all of the instrumentation and controls respond as expected. When testing a new CAMRAS unit, a few cases are run simulating vendor pre-delivery tests, to ensure that the unit has not been damaged in transit.

CAMRAS Phase 4A then tested a series of representative flight operations scenarios. Baseline cases were run at standard air flow rates and valve cycle time for various metabolic loads to provide direct comparisons to the performance of the other CAMRAS units in previous test series. Two additional baseline cases were run with the CAMRAS unit enclosed in an insulation blanket. This testing provided JSC computer modelers with data on the thermal effects of running a CAMRAS unit without environmental heat exchange, representing operations in an

$$
5
$$

American Institute of Aeronautics and Astronautics 
evacuated cabin. From the previous test series' results the JSC team had developed recommended operations parameters for each metabolic load. These were selected to maintain the dew point and $\mathrm{CO}_{2}$ levels in comfortable and acceptable ranges and to reduce blower power and ullage atmosphere loss from the standard air flow rates and valve cycle time. Many of the recommended parameters had been interpolated from actual test results, so in Phase 4A they were validated through testing. Similarly, the Orion Program had developed its own recommended operation parameters based on Hamilton Sundstrand-developed computer models of the vehicle atmosphere and ARS, including slightly different metabolic load profiles than the typical JSC CAMRAS testing. A set of test cases were run in Phase 4A to validate these computer model predictions.

Regeneration options were a major segment of the CAMRAS Phase 4A testing. A few test cases were run representing launchpad operations, where the CAMRAS unit would be regenerated by a stream of dry compressed air instead of by a vacuum source. Several such cases had been part of CAMRAS Phase 3 testing, but the new CAMRAS unit was different enough in its flow path design that the additional testing was needed to compare performance of the two designs. Regeneration by vacuum during orbital operations was also further investigated in Phase 4A. A rough correlation of CAMRAS efficiency versus vacuum pressure at the end of each half-cycle was generated in earlier test series. To build on that, in Phase 4A there was an effort to find the maximum vacuum line pressure that would allow the CAMRAS to keep up with normal high metabolic loads, such as a series of exercise periods, or a contingency case, such as a single CAMRAS unit providing life support for six crew members.

Finally, a number of Phase 4A test cases were run investigating the effects of the CAMRAS on typical vehicle trace contaminant gases, but those test cases are discussed in a separate paper at this conference.

\section{A. Pressure Drop Check}

As part of the functional checkouts, the pressure drop across the CAMRAS units at various process flow rates was tested. Figure 4 shows the average bed pressure drop measured for CAMRAS unit 3 and compares it to the equivalent data for CAMRAS units 1 and 2 in earlier test series. The pressure drop of unit 3 had been expected to be better than that of the other two test articles; however, a structural failure during the first assembly attempt was ameliorated by the addition of extra support material in the air flow channels, but at the cost of increased pressure drop.

\section{Average Pressure Drops Across CAMRAS Units}

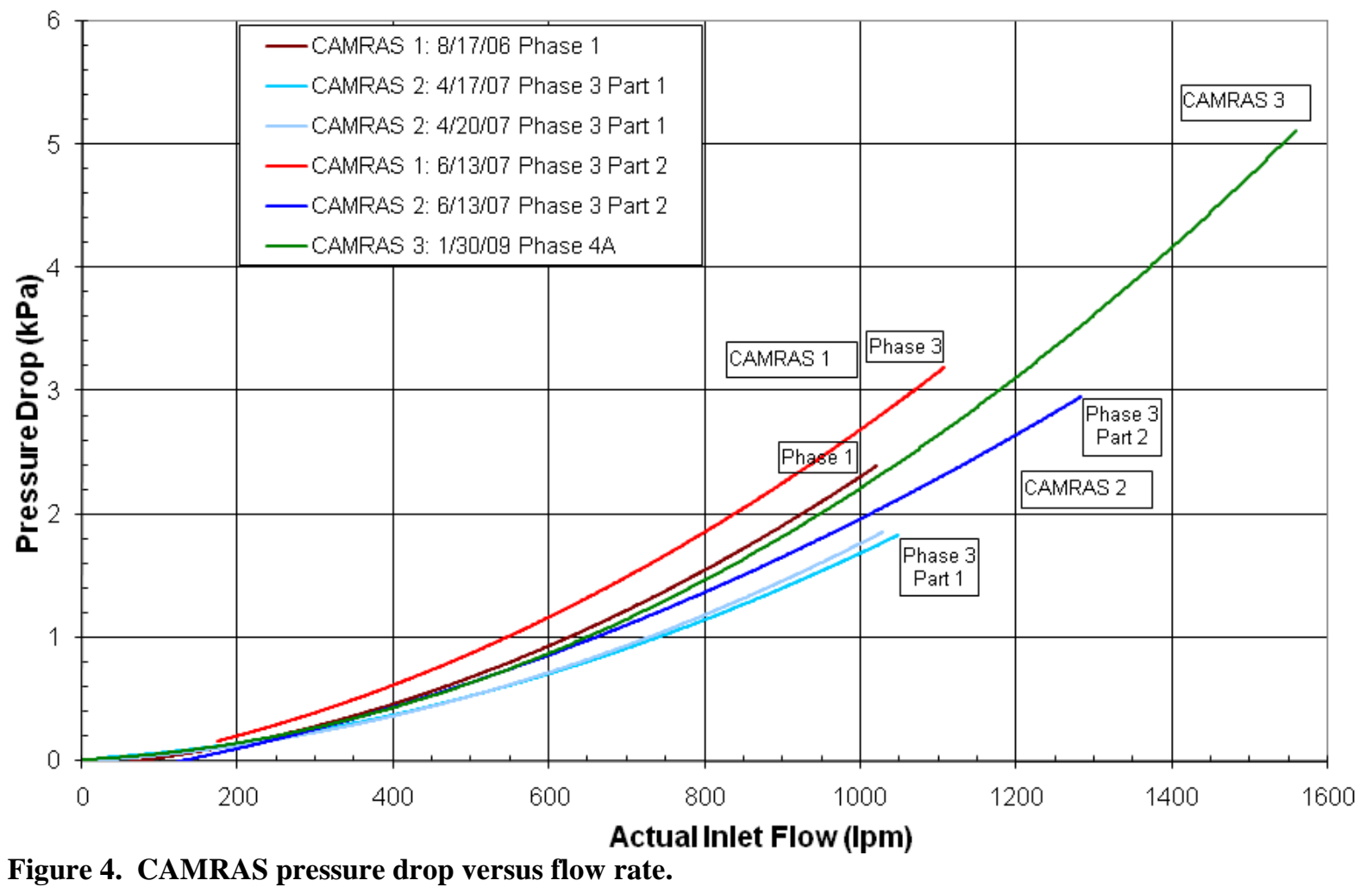




\section{B. Vendor Comparison Tests}

The vendor's test rig was configured such that CAMRAS inlet conditions were controlled to known setpoints and the outlet conditions were measured. There was no mixing volume and the exterior of the CAMRAS unit was exposed to laboratory temperatures. The vendor's vacuum system did not achieve vacuum pressures as low as the JSC test rig, and for CAMRAS unit 3 testing it was only configured for single-end desorption, which is a source for potentially significant differences in the comparison test results. In the JSC tests, the vendor's fixed inlet condition was simulated by controlling the $\mathrm{HMS} \mathrm{CO}_{2}$ and water input rates to maintain steady chamber conditions as the CAMRAS operated; metabolically-accurate loads were not used for this type of test. The differing CAMRAS exterior temperature and vacuum system factors were not countered.

Unfortunately, the vendor's CAMRAS unit 3 predelivery tests were not as close to the defined test case conditions as hoped. Not only were the temperatures outside the unit unrelated to the process air temperatures, but the process air temperatures were all significantly lower than specified. Taken as a whole, however, the results of the postdelivery tests at JSC can be considered roughly comparable to the predelivery tests at Hamilton Sundstrand, which satisfied the principal objective of these test cases: verifying functionality. Relative to the same test conditions run with earlier CAMRAS test articles, the new CAMRAS unit 3 generally performed comparably to the other two units.

\section{Baseline Performance Tests}

To establish the baseline performance of the new test article in the modified test rig, each type of HSIR standard metabolic load was examined with the vendor's original universal operation recommendations of $26 \mathrm{cfm}$ process air flow and 6.5-minute valve cycle times. Earlier JSC CAMRAS test series used $25 \mathrm{cfm}$ of process flow for easier development of uniform test matrices, but the Orion Program has been pursuing flow rates of $26 \mathrm{cfm}$ per CAMRAS unit in the vehicle. Therefore, beginning with Phase 4A, the CAMRAS test series changed the baseline flow rate to reflect the programmatic direction. The exercise metabolic profile was also run at $39 \mathrm{cfm}$ per CAMRAS unit to reflect the latest vehicle blower specification and operation plans, which called for that amount of flow during the crew's exercise period. Overall, the performance of CAMRAS unit 3 in these baseline tests (see Table 2) was comparable to the performance of unit 2 in the equivalent Phase 3 tests, even though unit 2 only had single-end vacuum desorption.

Table 2. Baseline operations test conditions and results.

\begin{tabular}{|l|c|c|c|c|c|c|}
\hline Simulated Crew Size & 4 & 4 & 4 & 4 & 6 & 6 \\
\hline $\begin{array}{l}\text { Crew Activity } \\
\text { Cimulated Number of Operational }\end{array}$ & 2 & 2 & 2 & 2 & 2 & 2 \\
\hline Rotary Valve Cycle Time & $6.5 \mathrm{~min}$ & $6.5 \mathrm{~min}$ & $6.5 \mathrm{~min}$ & $6.5 \mathrm{~min}$ & $6.5 \mathrm{~min}$ & $6.5 \mathrm{~min}$ \\
\hline CAMRAS Inlet Flow Rate & $740 \mathrm{lpm}$ & $740 \mathrm{lpm}$ & $740 \mathrm{lpm}$ & $1100 \mathrm{lpm}$ & $740 \mathrm{lpm}$ & $740 \mathrm{lpm}$ \\
\hline $\begin{array}{l}\text { Final Steady-State } \mathrm{CO}_{2} \text { Partial } \\
\text { Pressure }\end{array}$ & $123 \mathrm{~Pa}$ & $177 \mathrm{~Pa}$ & $175 \mathrm{~Pa}$ & $147 \mathrm{~Pa}$ & $172 \mathrm{~Pa}$ & $253 \mathrm{~Pa}$ \\
\hline Final Steady-State Dew Point & $-8.06^{\circ} \mathrm{C}$ & $-1.11^{\circ} \mathrm{C}$ & $-0.67^{\circ} \mathrm{C}$ & $-3.67^{\circ} \mathrm{C}$ & $-3.89^{\circ} \mathrm{C}$ & $4.06^{\circ} \mathrm{C}$ \\
\hline Exercise Start $\mathrm{CO}_{2}$ Partial Pressure & N/A & N/A & $191 \mathrm{~Pa}$ & $140 \mathrm{~Pa}$ & N/A & N/A \\
\hline $\begin{array}{l}\text { Exercise First Peak } \mathrm{CO}_{2} \text { Partial } \\
\text { Pressure }\end{array}$ & N/A & N/A & $368 \mathrm{~Pa}$ & $320 \mathrm{~Pa}$ & N/A & N/A \\
\hline $\begin{array}{l}\text { Exercise Highest Peak } \mathrm{CO}_{2} \text { Partial } \\
\text { Pressure }\end{array}$ & N/A & N/A & $420 \mathrm{~Pa}$ & $367 \mathrm{~Pa}$ & N/A & N/A \\
\hline Exercise Start Dew Point & N/A & N/A & $-0.44^{\circ} \mathrm{C}$ & $-3.28^{\circ} \mathrm{C}$ & N/A & N/A \\
\hline Exercise First Peak Dew Point & N/A & N/A & $11.78^{\circ} \mathrm{C}$ & $9.44^{\circ} \mathrm{C}$ & N/A & N/A \\
\hline Exercise Highest Peak Dew Point & N/A & N/A & $17.67^{\circ} \mathrm{C}$ & $13.83^{\circ} \mathrm{C}$ & N/A & N/A \\
\hline
\end{tabular}

\section{Insulated CAMRAS}

A scenario requested by the analysis and modeling team was intended to more clearly illustrate heat transfer effects within the CAMRAS and between the CAMRAS and its environment. In this scenario, instead of being exposed to the chamber air on all sides as in all previous test cases, the CAMRAS unit was completely encased in a blanket of Nomex insulation while two different baseline test cases were run, representing high and low metabolic loads. The bottom surface of the CAMRAS was always thermally isolated from the supporting metal table by an air gap created by $6.5 \mathrm{~mm}$-thick Teflon ${ }^{\circledR}$ strips supporting the unit's mounting strips along the long edges of the 
canister. The results of the two insulated CAMRAS test cases were analogous to the baseline test cases. The steady-state $\mathrm{CO}_{2}$ levels were effectively the same, and the steady-state dew points were slightly lower than in the baseline tests (within $0.4^{\circ} \mathrm{C}$ ). The differences were small, so the tradeoff for the weight of insulating the units on the vehicle would almost certainly not be worthwhile. That said, the data from these two test cases should prove useful to those developing computer models of CAMRAS thermodynamics.

\section{E. Recommended Operations}

The cabin $\mathrm{CO}_{2}$ level should be maintained at a partial pressure below $500 \mathrm{~Pa}(3.8 \mathrm{mmHg})$ average over the long term. The chamber dew point should be maintained above $0.6^{\circ} \mathrm{C}\left(33^{\circ} \mathrm{F}\right)$ based on an Orion requirement to maintain at least $25 \%$ relative humidity in the cabin (on daily average) at the typical $21^{\circ} \mathrm{C}\left(70^{\circ} \mathrm{F}\right)$ cabin temperature used in these tests. The higher the cabin temperature, the higher the minimum dew point value required to maintain the minimum 25\% relative humidity. The higher the relative humidity (up to the maximum dew point), the more comfortable the crew for long durations. The maximum cabin dew point target of $7.2^{\circ} \mathrm{C}\left(45^{\circ} \mathrm{F}\right)$ was intended to prevent condensation on the uninsulated Orion coolant loops, which would run at $8.3^{\circ} \mathrm{C}\left(47^{\circ} \mathrm{F}\right)$. The Orion Program conceded that condensation could be allowed for transient periods of high water load, such as during exercise periods, with the assumptions that the water would preferentially condense inside the cabin air heat exchanger (anticipated to be the coldest spot in the cabin) and that the water would evaporate shortly after the high water load period, when the CAMRAS had had the opportunity to return the cabin dew point below the condensation temperature. In general, controlling the dew point within this relatively narrow band in testing has turned out to be the most significant driver of process flow rate and cycle time. High $\mathrm{CO}_{2}$ levels were never an issue in nominal scenario tests so long as the water vapor was sufficiently controlled. System operational settings to maintain the cabin moisture and $\mathrm{CO}_{2}$ levels in the desired ranges were recommended by the JSC air team based on earlier JSC CAMRAS test series data gathered while using HSIR metabolic loads, and those recommendations were tested in Phase 4A. Lower flow rates and longer CAMRAS valve cycle times were incorporated into the recommendations in the interest of minimizing power consumption and heat generation by the ARS blower as well as that of minimizing ullage gas loss each time the valve cycled.

The test cases (Table 3) all validated the recommended operational settings, as the chamber dew points and $\mathrm{CO}_{2}$ levels were comfortably within the specified ranges, and all except the exercise case used lower flow rates and longer cycle times than both the baseline cases and the projected operations model cases (see next section). The exercise case dew points exceeded the limits, as expected, but the shorter cycle time induced lower peak dew points than in the model projection cases or the baseline cases, and as discussed in earlier reports, spreading the exercise periods further apart than the tested 15 minutes would further reduce subsequent peak values.

Table 3. Recommended operations test conditions and results.

\begin{tabular}{|l|c|c|c|c|c|}
\hline Simulated Crew Size & 4 & 4 & 4 & 6 & 6 \\
\hline Crew Activity & sleep & nominal & exercise & sleep & nominal \\
\hline $\begin{array}{l}\text { Simulated Number of Operational } \\
\text { CAMRAS Units }\end{array}$ & 2 & 2 & 2 & 2 & 2 \\
\hline Rotary Valve Cycle Time & $15 \mathrm{~min}$ & $10 \mathrm{~min}$ & $3 \mathrm{~min}$ & $15 \mathrm{~min}$ & $10 \mathrm{~min}$ \\
\hline CAMRAS Inlet Flow Rate & $210 \mathrm{lpm}$ & $420 \mathrm{lpm}$ & $1100 \mathrm{lpm}$ & $280 \mathrm{lpm}$ & $637 \mathrm{lpm}$ \\
\hline Final Steady-State $\mathrm{CO}_{2}$ Partial Pressure & $396 \mathrm{~Pa}$ & $279 \mathrm{~Pa}$ & $127 \mathrm{~Pa}$ & $396 \mathrm{~Pa}$ & $333 \mathrm{~Pa}$ \\
\hline Final Steady-State Dew Point & $4.83^{\circ} \mathrm{C}$ & $4.06^{\circ} \mathrm{C}$ & $-4.61^{\circ} \mathrm{C}$ & $6.67^{\circ} \mathrm{C}$ & $6.11^{\circ} \mathrm{C}$ \\
\hline Exercise Start $\mathrm{CO}_{2}$ Partial Pressure & N/A & N/A & $156 \mathrm{~Pa}$ & N/A & N/A \\
\hline Exercise First Peak $\mathrm{CO}_{2}$ Partial Pressure & N/A & N/A & $276 \mathrm{~Pa}$ & N/A & N/A \\
\hline Exercise Highest Peak $\mathrm{CO}_{2}$ Partial Pressure & N/A & N/A & $284 \mathrm{~Pa}$ & N/A & N/A \\
\hline Exercise Start Dew Point & N/A & N/A & $-1.61^{\circ} \mathrm{C}$ & N/A & N/A \\
\hline Exercise First Peak Dew Point & N/A & N/A & $8.44^{\circ} \mathrm{C}$ & N/A & N/A \\
\hline Exercise Highest Peak Dew Point & N/A & N/A & $12.56^{\circ} \mathrm{C}$ & N/A & N/A \\
\hline
\end{tabular}

\section{F. Orion Program Model Validation}

Hamilton Sundstrand developed a set of anticipated Orion cabin and ARS operation conditions for the Orion prime contractor, Lockheed Martin, using a computer model that is believed to have been developed based on Hamilton's CAMRAS development laboratory test data. Limited information on these cases was received by the JSC air team on July 16, 2008. To provide context for relating the results of various JSC CAMRAS tests to the Hamilton Sundstrand models, JSC ran several test cases in Phase 4A emulating the model's temperature and 
metabolic loads. A full set of representative metabolic cases were tested, in addition to a case simulating a crew of 6 donning and doffing their space suits.

Several of the assumptions that went into the modeled conditions were different than those typically used by the JSC team. The cabin temperatures varied depending on the crew activity level. The metabolic loads (Table 4) were based on basic thermal metabolic rates rather than the separate $\mathrm{CO}_{2}$ and moisture generation rates specified in the HSIR. The exercise

Table 4. Orion model metabolic loads.

\begin{tabular}{|c|c|c|c|c|c|c|}
\hline $\begin{array}{l}\text { Crew Size } \\
\text { \& Activity }\end{array}$ & 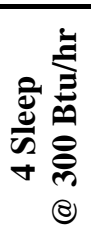 & 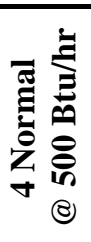 & 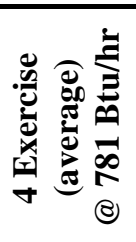 & 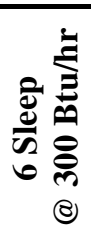 & 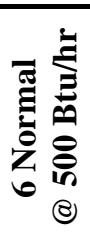 & 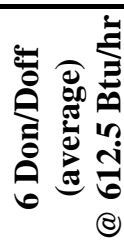 \\
\hline $\begin{array}{l}\text { Metabolic } \mathrm{CO}_{2} \\
\text { Generation } \\
\text { Rate (g/min) }\end{array}$ & 1.83 & 1.53 & 2.38 & 2.74 & 2.28 & 2.80 \\
\hline $\begin{array}{l}\text { Metabolic } \mathrm{H}_{2} \mathrm{O} \\
\text { Generation } \\
\text { Rate (g/min) }\end{array}$ & 2.03 & 3.51 & 8.32 & 3.05 & 5.26 & 8.78 \\
\hline
\end{tabular}
and don/doff cases were run at a constant average metabolic rate, unlike the standard JSC exercise cases, which used a profile of increasing and decreasing water injection rates. The vacuum pressure was assumed to be equivalent to that typically achieved in the CAMRAS development laboratory at Hamilton Sundstrand, around $80-95$ Pa. The model also assumed different cabin pressures for various scenarios, but the effect of reduced cabin pressure on CAMRAS operations is not yet well understood. Although the reduced pressures could not be incorporated in JSC's Phase 4A tests, these scenarios are targeted for JSC testing at reduced pressure in 2010.

Hamilton Sundstrand's model assumed that the third Orion CAMRAS unit is used in heavy moisture loading conditions, such as exercise periods, and that $78 \mathrm{cfm}$ of available air flow was divided between the three units. However, the Phase 4A JSC test rig was limited to a single test article and volume fillers that could only halve the chamber free volume, not reduce it to one third of the free volume. The JSC tests, therefore, modified the Hamilton conditions for two test cases (suit don/doff and exercise) by assuming that the third vehicle CAMRAS unit would be completely reserved for emergency capability. The Hamilton model also assumed that only one CAMRAS unit would operate during sleep cases; the Phase 4A test reflected that assumption by using the single test article in the full chamber volume (volume fillers removed) with the full metabolic rates.

The model validation test results are summarized in Table 5. For the four-person sleep case, the $\mathrm{CO}_{2}$ level was still rising when the test case was ended, but it had run for the maximum 10 hours. Only the six-person sleep case closely matched the model projections, but it is unclear how much effect the difference in the chamber atmospheric pressure had, if any. In the two high metabolic load cases, the test article performed notably less effectively than the model had projected, though the model did assume three operating CAMRAS units instead of the tested simulation of two units.

Table 5. Orion model validation test conditions and results.

\begin{tabular}{|c|c|c|c|c|c|c|}
\hline Simulated Crew Size & 4 & 4 & 4 & 6 & 6 & 6 \\
\hline Crew Activity & sleep & nominal & exercise & sleep & nominal & don/doff \\
\hline $\begin{array}{l}\text { Simulated Number of } \\
\text { Operational CAMRAS Units }\end{array}$ & 1 & 2 & 2 & 1 & 2 & 2 \\
\hline Rotary Valve Cycle Time & $26 \min$ & $10 \mathrm{~min}$ & $5 \min$ & $16 \mathrm{~min}$ & $5 \mathrm{~min}$ & $5 \mathrm{~min}$ \\
\hline CAMRAS Inlet Flow Rate & $740 \mathrm{lpm}$ & $740 \mathrm{lpm}$ & $1100 \mathrm{lpm}$ & $740 \mathrm{lpm}$ & $740 \mathrm{lpm}$ & $1100 \mathrm{lpm}$ \\
\hline $\begin{array}{l}\text { Cabin Temperature for Projected } \\
\text { Results }\end{array}$ & $21^{\circ} \mathrm{C}$ & $24^{\circ} \mathrm{C}$ & $27^{\circ} \mathrm{C}$ & $21^{\circ} \mathrm{C}$ & $24^{\circ} \mathrm{C}$ & $27^{\circ} \mathrm{C}$ \\
\hline $\begin{array}{l}\text { Cabin Pressure for Projected } \\
\text { Results }\end{array}$ & $70.3 \mathrm{kPa}$ & $70.3 \mathrm{kPa}$ & $70.3 \mathrm{kPa}$ & $101.4 \mathrm{kPa}$ & $101.4 \mathrm{kPa}$ & $101.4 \mathrm{kPa}$ \\
\hline Projected $\mathrm{CO}_{2}$ Partial Pressure & $329 \mathrm{~Pa}$ & $205 \mathrm{~Pa}$ & $203 \mathrm{~Pa}$ & $541 \mathrm{~Pa}$ & $295 \mathrm{~Pa}$ & $240 \mathrm{~Pa}$ \\
\hline Projected Dew Point & $1.56^{\circ} \mathrm{C}$ & $6.61^{\circ} \mathrm{C}$ & $12.11^{\circ} \mathrm{C}$ & $4.89^{\circ} \mathrm{C}$ & $10.94^{\circ} \mathrm{C}$ & $12.89^{\circ} \mathrm{C}$ \\
\hline Final Chamber Temperature & $21.3^{\circ} \mathrm{C}$ & $24.1^{\circ} \mathrm{C}$ & $26.9^{\circ} \mathrm{C}$ & $21.3^{\circ} \mathrm{C}$ & $24.1^{\circ} \mathrm{C}$ & $26.9^{\circ} \mathrm{C}$ \\
\hline $\begin{array}{l}\text { Final Steady-State } \mathrm{CO}_{2} \text { Partial } \\
\text { Pressure }\end{array}$ & $\begin{array}{c}6 \text { cycle avg.: } \\
445 \mathrm{~Pa} \\
\end{array}$ & $227 \mathrm{~Pa}$ & $243 \mathrm{~Pa}$ & $533 \mathrm{~Pa}$ & $273 \mathrm{~Pa}$ & $283 \mathrm{~Pa}$ \\
\hline Final Steady-State Dew Point & $1.11^{\circ} \mathrm{C}$ & $5.72^{\circ} \mathrm{C}$ & $13.72^{\circ} \mathrm{C}$ & $4.44^{\circ} \mathrm{C}$ & $10.00^{\circ} \mathrm{C}$ & $14.39^{\circ} \mathrm{C}$ \\
\hline
\end{tabular}




\section{G. Launchpad Operations}

Providing a vacuum source of sufficient quality to regenerate the CAMRAS on the launchpad is impractical. Instead, the device can be regenerated by a flow of compressed gas that is low in $\mathrm{CO}_{2}$ and moisture. During CAMRAS Phase 3 testing, it was demonstrated that the purge gas flow should be equal to or higher than the process air flow rate for acceptable $\mathrm{CO}_{2}$ and $\mathrm{H}_{2} \mathrm{O}$ scrubbing performance and that the CAMRAS valve cycle time should be short. The performance of the new CAMRAS unit was first baselined with crews of both sizes, and then a matrix of cases was tested with various combinations of process air flow rate, purge air flow rate, and cycle time to refine operating parameter recommendations. A simulated crew of six on two CAMRAS units was used for the matrix cases to provide worst-case results, and the matrix was based on the process flow rates projected to be available in the vehicle. The results of these matrix cases are presented in Table 6. All of the matrix cases yielded chamber conditions within the target ranges. The four-person case at $740 \mathrm{lpm}$ process and purge flows with 6.5 minute cycle time yielded an acceptable $\mathrm{CO}_{2}$ partial pressure $\left(\mathrm{ppCO}_{2}\right)$ of $280 \mathrm{~Pa}$ and a slightly low dew point of $0.33^{\circ} \mathrm{C}$.

Table 6. Launchpad test results matrix for six simulated crew.

\begin{tabular}{|c|c|c|c|}
\hline Process Flow : Purge Flow & \multirow{2}{*}{740 lpm : 740 lpm } & \multirow{2}{*}{740 lpm : 1100 lpm } & \multirow{2}{*}{1100 lpm : 1100 lpm } \\
\hline $\begin{array}{l}\text { Cycle Time } \\
\end{array}$ & & & \\
\hline 3 minutes & $\begin{array}{c}361 \mathrm{~Pa} \mathrm{ppCO}_{2} \\
5.39^{\circ} \mathrm{C} \text { dew point }\end{array}$ & $\begin{array}{c}305 \mathrm{~Pa} \mathrm{ppCO}_{2} \\
3.72^{\circ} \mathrm{C} \text { dew point }\end{array}$ & $\begin{array}{c}285 \mathrm{~Pa} \mathrm{ppCO}_{2} \\
1.33^{\circ} \mathrm{C} \text { dew point }\end{array}$ \\
\hline 6.5 minutes & $\begin{array}{c}391 \mathrm{~Pa} \mathrm{ppCO}_{2} \\
5.72^{\circ} \mathrm{C} \text { dew point }\end{array}$ & $\begin{array}{c}345 \mathrm{~Pa} \mathrm{ppCO}_{2} \\
4.78^{\circ} \mathrm{C} \text { dew point }\end{array}$ & $\begin{array}{c}305 \mathrm{~Pa} \mathrm{ppCO}_{2} \\
2.67^{\circ} \mathrm{C} \text { dew point }\end{array}$ \\
\hline
\end{tabular}

The initial conditions of these gas purge cases were designed to reflect typical Florida launch site atmospheric conditions, and the test cases ran for the maximum closed-hatch launch pad hold duration of 6 hours, or until steadystate was achieved, whichever came first. The purge cases then transitioned to an ascent scenario: after the system reached steady-state conditions, the gas flow was shut off, and the length of time between purge shutoff and chamber $\mathrm{ppCO}_{2}$ exceeding $1010 \mathrm{~Pa}(7.6 \mathrm{mmHg})$ was determined. This helps define the maximum time window that would be available between liftoff and the beginning of vacuum CAMRAS regeneration. Air flow rate and CAMRAS cycle time affected the steady-state levels during the gas purge. However, test data showed that the time to exceed $1010 \mathrm{~Pa} \mathrm{ppCO}_{2}$ from the gas purge cutoff time appeared to be directly related only to the metabolic injection rate and the steady-state chamber $\mathrm{ppCO}_{2}$ at cutoff, and independent of flow rate and cycle time. For the six-crew test cases, this ranged from about 60 - 75 minutes, and for the four-crew case it was about 100 minutes.

\section{H. Vacuum Pressure Sensitivity}

Ideally, the vacuum line pressure should be as low as possible to allow maximum $\mathrm{CO}_{2}$ and $\mathrm{H}_{2} \mathrm{O}$ desorption off of each CAMRAS bed within the cycle period. However, the CAMRAS units might not be granted an optimal installation within the vehicle, where the ideal would be a large, short, straight line to space. The importance of the vacuum pressure on the CAMRAS operating performance must be quantified to help lobby for CAMRAS vacuumaccess proximity as a vehicle is designed and to adjust operational parameter recommendations based on the actual vacuum pressure available. A number of degraded vacuum cases were tested during CAMRAS Phase 1, and in CAMRAS Phase 3 an extension of this test was performed. Further experimental insight was desired in Phase 4A, particularly in contingency scenarios and with high metabolic loads.

A full six-person nominal load on a single CAMRAS unit, representing contingency operations in the case of multiple failures within the Orion ARS, was tested at four different vacuum levels (2.4, 1.2, 0.7, $0.1 \mathrm{kPa})$ and two air flow rates $(740,1100 \mathrm{lpm})$. A simulated four-person exercise scenario was tested at three different vacuum levels $(1.3,0.7,0.1 \mathrm{kPa})$. The base pressure is the pressure in the vacuum lines nearest the CAMRAS units before any desorption begins; the test cases were initially configured to particular base pressures.

None of the single-unit contingency test cases except the $0.1 \mathrm{kPa}(1 \mathrm{mmHg})$ vacuum base pressure cases were allowed to continue long enough to reach steady-state, as the $\mathrm{CO}_{2}$ levels were significantly higher than would be allowed for any length of time in the spacecraft, even in a contingency situation, and they were rising steadily. The $\mathrm{ppCO}_{2} \mathrm{~s}$ in the $0.1 \mathrm{kPa}$ cases were higher than optimal $(620-690 \mathrm{~Pa}=4.65-5.16 \mathrm{mmHg})$, and condensation would occur in the vehicle at the steady-state dew points $\left(11.9-15.2^{\circ} \mathrm{C}\right)$, but the crew could survive in those conditions for an extended period. This means that, for safe contingency operations with the largest crew complement, the base vacuum pressure available at the CAMRAS vacuum interface on the vehicle should be lower than $0.7 \mathrm{kPa}$ $(5 \mathrm{mmHg})$, and ideally nearer to or lower than $0.1 \mathrm{kPa}$. These tests were designed before the decision was made to reduce the maximum Orion crew size to four people, so there may be more margin on the maximum reasonable base vacuum pressure to support this critical contingency operation condition. Similarly, the exercise cases yielded peak 
$\mathrm{CO}_{2}$ levels far higher than considered safe for extended periods for the $1.3 \mathrm{kPa}(10 \mathrm{mmHg})$ and $0.7 \mathrm{kPa}$ vacuum base pressure cases. The $0.1 \mathrm{kPa}$ vacuum base pressure case was acceptable for $\mathrm{ppCO}_{2}$ (highest peak $409 \mathrm{~Pa}=3.07$ $\mathrm{mmHg}$ ) and very high on dew point $\left(15.4^{\circ} \mathrm{C}\right)$, so these results of a normal flight scenario corroborate the contingency scenario need for base vacuum pressure of near to or lower than $0.1 \mathrm{kPa}$ in order to maintain $\mathrm{CO}_{2}$ and moisture at reasonable levels in the cabin atmosphere.

\section{Summary, Conclusions, and Future Work}

Two and a half months of ambient-pressure testing of the baseline Orion ARS technology was completed in the spring of 2009 with a redesigned CAMRAS test article as part of the CAMRAS Phase 4A test series. The new test article and its new test rig were checked for basic functionality, and a set of standard baseline tests was run with the system, as was a set of tests using recommended operation parameters developed in previous phases of the CAMRAS test series. Tests mimicking Orion Program computer models of the vehicle ARS with CAMRAS technology were performed to provide validation feedback to the Program regarding the accuracy of the models. Launchpad regeneration with a flow of pressurized gas was studied with the revised system design, and several combinations of process flow rate and purge gas flow rate were investigated to help identify the most appropriate operational settings. High metabolic water load cases were tested with varying levels of vacuum regeneration in an effort to determine the minimum performance criteria for the CAMRAS vacuum supply in the vehicle, which can help guide the vacuum plumbing designers.

Earlier testing had demonstrated that, for launchpad operations, the flow rate of pressurized purge gas should be equal to or greater than the process flow rate, and the cycle time should be short. Phase 4A tests validated this and provided more matrix data useful for vehicle specification and design.

Recommendations for CAMRAS operational conditions developed from the prior three phases of CAMRAS testing proved good in Phase 4A tests. The recommended flow rates and CAMRAS valve cycle times were generally lower and slower, respectively, than the Program-projected vehicle operations. The test team maintains its recommendation that the third flight CAMRAS unit should be reserved as a spare whenever possible. Similarly, rather than using only one unit during sleep periods, two units should be used to prevent unbalanced loading of the beds in the idle unit, which would significantly compromise system performance for a period after wakeup or in a contingency transition period. Based on these operational philosophies, the test team suggests that the low flow rate on the vehicle fans should be specified as $425 \mathrm{lpm}(15 \mathrm{cfm})$ instead of $736 \mathrm{lpm}(26 \mathrm{cfm})$ to maintain the cabin dew point at a high enough level for crew comfort during nominal and sleep metabolic load periods. The team also recommends a very short CAMRAS valve cycle time - on the order of 3 minutes - during exercise periods to minimize the cabin air moisture peaks. These recommendations are based on HSIR metabolic rates and vehicle vacuum pressure at the CAMRAS units comparable to that used in JSC tests (typically $33 \mathrm{~Pa}(0.25 \mathrm{mmHg})$ or lower). Testing showed that this vacuum base pressure must be around or below $1 \mathrm{mmHg}$ in order to support both single-CAMRAS contingency operations and exercise metabolic loads. Some differences were observed between the resultant cabin conditions of the Orion Program computer models and the Phase 4A validation tests, but further investigation at reduced pressure will be required to better understand whether this is a systemic discrepancy in the model, a result of the ambient pressure difference, or simply slight variation that could be expected from case to case in any test.

Overall, the design changes between the first two CAMRAS test articles and the newest one have resulted in similar performance. The CAMRAS technology remains capable of supporting a wide range of cabin conditions, but there is room for refinement to the vehicle design of other aspects of the ARS to make the most effective use of the technology. Further planned tests of CAMRAS units in reduced-pressure environments and with more human test crews will help further refine the results and recommendations developed from these CAMRAS Phase 4A tests. CAMRAS Phase 4B in 2010 will examine many of the test scenarios discussed here, but in pressure environments representing Orion Lunar transit (70 kPa, $10.2 \mathrm{psia}$ ) and Altair Lunar surface (57 kPa, $8.3 \mathrm{psia}$ ) operations. Another series of tests is planned for 2011 that would examine real humans in space suits hooked to a closed CAMRAS process loop at suit pressure (30 kPa, $4.3 \mathrm{psid}$ ), as well as real humans in an Orion-sized chamber at the two reduced cabin pressures with two CAMRAS units.

\section{Acknowledgments}

The authors would like to acknowledge Tim Nalette, Bill Papale, and Bryan Murach of Hamilton Sundstrand for providing the test article and preliminary test data as well as technical support during the JSC tests and subsequent analysis insights. JSC Test Facility Engineers Matt Blackmer, Peter Masi, Adrian Franco, and Jeremiah Nassif

designed and directed the facility modifications, and Chamber Operator Technician Mitch Sweeney led the test rig 
buildup effort. The JSC ELS Air Revitalization team (Mary Walsh, Jeff Sweterlitsch, Melissa Campbell, Amy (Lin) Button, Su Curley, and Craig Broerman, plus technical consultants John Graf, Kevin Lange, Bruce Conger, and Rama kumar Allada) was instrumental in helping design the test points. Amy Button, Melissa Campbell, Su Curley, and Matthew Stubbe conducted the tests, and Jeff Sweterlitsch provided Amy Button assistance with data analysis. NASA's ELS Program, Constellation Program, and Crew and Thermal Systems Division all helped fund the JSC CAMRAS testing program. This paper would not have been possible without all their help.

\section{References}

${ }^{1}$ Lin, A., "CAMRAS Phase 4A Quick-Look Test Report," CTSD-ADV-731, Johnson Space Center, Houston, TX, 2009.

${ }^{2}$ National Aeronautics and Space Administration, "Constellation Program Human-Systems Integration Requirements, Rev. B, CxP 70024, 2008. 